\title{
Prevalence of depressive symptoms in urban primary care settings: Botswana
}

\begin{tabular}{|c|c|}
\hline $\begin{array}{l}\text { Authors: } \\
\text { Keneilwe Mot } \\
\text { Keneilwe Mol } \\
\text { Grace N. Wam }\end{array}$ & $\begin{array}{l}\text { hatlhedi }{ }^{1} \text { (D) } \\
\text { batsi }{ }^{2} \text { (D) } \\
\text { bua }^{3} \text { (I) }\end{array}$ \\
\hline $\begin{array}{l}\text { Affiliations: } \\
{ }^{1} \text { Department } \\
\text { Medicine and } \\
\text { Faculty of Me } \\
\text { University of } \\
\text { Gaborone, Bo }\end{array}$ & $\begin{array}{l}\text { f Family } \\
\text { Public Health, } \\
\text { dicine, } \\
\text { otswana, } \\
\text { swana }\end{array}$ \\
\hline $\begin{array}{l}{ }^{2} \text { Department } \\
\text { Faculty of Me } \\
\text { University of } \\
\text { Gaborone, Bo }\end{array}$ & $\begin{array}{l}\text { f Psychiatry, } \\
\text { licine, } \\
\text { otswana, } \\
\text { swana }\end{array}$ \\
\hline $\begin{array}{l}{ }^{3} \text { Department } \\
\text { School of Clini } \\
\text { University of } \\
\text { Durban, South }\end{array}$ & $\begin{array}{l}\text { f Psychiatry, } \\
\text { cal Medicine, } \\
\text { waZulu-Natal, } \\
\text { Africa }\end{array}$ \\
\hline $\begin{array}{l}\text { Correspondin } \\
\text { Keneilwe Mot } \\
\text { kennymotlhat } \\
\text { com }\end{array}$ & $\begin{array}{l}\text { author: } \\
\text { hatlhedi, } \\
\text { hedi@gmail. }\end{array}$ \\
\hline $\begin{array}{l}\text { Dates: } \\
\text { Received: } 26 \\
\text { Accepted: } 01 \\
\text { Published: } 07\end{array}$ & $\begin{array}{l}\text { ct. } 2020 \\
\text { Mar. } 2021 \\
\text { May } 2021\end{array}$ \\
\hline $\begin{array}{l}\text { How to cite th } \\
\text { Motlhatlhedi } \\
\text { Wambua GN. } \\
\text { depressive sy } \\
\text { urban primar } \\
\text { Botswana. Afr } \\
\text { Health Care F } \\
\text { 2021;13(1), a } \\
\text { https://doi.or } \\
\text { phcfm.v13i1.2 }\end{array}$ & $\begin{array}{l}\text { is article: } \\
\text { K, Molebatsi K, } \\
\text { Prevalence of } \\
\text { nptoms in } \\
\text { care settings: } \\
\text { J Prm } \\
\text { m Med. } \\
822 \text {. } \\
\text { /10.4102/ } \\
822\end{array}$ \\
\hline $\begin{array}{l}\text { Copyright: } \\
\text { (C) 2021. The A } \\
\text { Licensee: AOS } \\
\text { is licensed unc } \\
\text { Creative Comr } \\
\text { Attribution Lic }\end{array}$ & $\begin{array}{l}\text { uthors. } \\
\text { S. This work } \\
\text { ler the } \\
\text { nons } \\
\text { ense. }\end{array}$ \\
\hline Read online: & \\
\hline 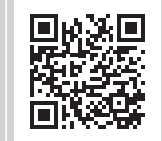 & $\begin{array}{l}\text { Scan this QR } \\
\text { code with your } \\
\text { smart phone or } \\
\text { mobile device } \\
\text { to read online. }\end{array}$ \\
\hline
\end{tabular}

Background: The prevalence of depression is estimated to be high in primary care settings, especially amongst people with chronic diseases. Early identification and management of depression can improve chronic disease outcomes and quality of life, however, there are many missed opportunities in primary care.

Aim: This study aimed to determine the prevalence and correlates of depression and depressive symptoms in two urban primary care settings.

Setting: The study was conducted at two primary care facilities in the capital city of Botswana.

Methods: We administered a demographic questionnaire and the Patient Health Questionnaire-9 (PHQ-9) to adults attending two primary care facilities. The association between depressive symptoms and demographic variables was determined using Chi-square; level of significance was set at 0.05 . We carried out a multivariate analysis using KruskalWallis test to determine the association between demographic characteristics and depression.

Results: A sample of 259 participants were recruited (66.8\% women, median age 32). The mean PHQ-9 score was 8.71 . A total of $39.8 \%$ of participants screened positive for depression at a cut-off of $9.0 \%$ and $35.1 \%$ at a cut-off of 10 . Depressive symptoms were significantly associated with employment status and income using the Kruskal-Wallis test, $\chi^{2}(1)=5.649, p=0.017$.

Conclusion: The high rates of depressive symptoms amongst the study population highlight the need for depression screening in primary care settings. The association between unemployment and income underscore the impact of socio-economic status on mental health in this setting.

Keywords: epression; depressive symptoms; PHQ-9, prevalence; urban; primary care; Botswana; Africa.

\section{Background}

The World Health Organization (WHO) ranks depression as a leading cause of non-fatal health loss and the fourth leading cause of disability globally. ${ }^{1,2}$ Estimates suggest that $4 \%-15 \%$ of people suffer from depression at some point in their lives, whilst the point prevalence of depression is estimated to be between $5 \%$ and $10 \%{ }^{1,3,4,5}$ Higher depression prevalence rates ranging from $4 \%$ to $50 \%$, have been reported in some sub-Saharan Africa (SSA) settings. ${ }^{1,4,6}$ Furthermore, the prevalence of depression has been found to be higher amongst people with chronic diseases such as HIV, diabetes mellitus and cardiovascular diseases, many of whom receive care in primary care centers. , $, 7,8,9,10^{-10}$

The characteristic symptoms of depression include sadness, anhedonia and self-harm; the effects of the disorder extend beyond the individual and may negatively affect family life, occupational and academic functioning and the society at large..$^{1,9,11,12}$ Although the mechanism is unclear, there is evidence that the bidirectional relationship between depressive disorders and chronic diseases may worsen physical and psychological outcome and increase the cost of healthcare. ${ }^{8,11,13}$ On the one hand, it is possible that the negative symptoms of depression result in poor adherence to medications and life-style modifications, which are important for improved chronic disease outcomes. On the other hand being diagnosed with a chronic disease further worsens the anxiety and negative self-assessment of a patient with depression. ${ }^{8}$

Early identification and management of depression may help to curb the negative impact of depression and improve the quality of life of those who suffer from the condition. ${ }^{14,15}$ The WHO 
reports that up to $85 \%$ of patients with the disorder do not receive appropriate care, many of whom are in low- and middle-income countries (LMICs). ${ }^{16,17}$ This insufficiency in care may be attributable to a shortage of adequately skilled mental health staff, competing health concerns and limited consultation times because of the low healthcare workers to population ratios in LMICs, particularly there is a shortage of adequately skilled mental healthcare workers. ${ }^{16,18,19}$ Patients with depression may initially present with somatic symptoms. Evidence indicates that depressed patients with predominantly somatic symptoms are less likely to be diagnosed with depression than those who present solely with psychological or mood symptoms. ${ }^{20,21}$ Most patients with depression (regardless of the predominant symptoms) are initially consulted at primary care level; primary care clinicians are therefore best suited to identify mild and moderate forms of the illness early on and to initiate appropriate management. The use of depression screening tools may enhance the ability of primary care clinicians in LMICs to identify patients with depression.

Screening for depression in primary care settings requires an understanding of the factors which predisposed patients to depression. Previous research has reported various predictors of depression, including a family history of depression or mental illness, chronic illness, substance abuse, low socioeconomic status, female gender and older age. ${ }^{4,12,19,22,23}$ The strength of the association of these factors with depression may vary between populations, for example, low income was associated with depression in high-income countries but not in LMICs, whilst lower education status was associated with depression in some Asian countries, but not in others. ${ }^{4}$ In addition, even though the presence or absence of a factor may be positively associated with depression, the inverse may not necessarily be true. For example, in one South African study, unemployment and low income were positively associated with depression, but surprisingly the relationship with education was not that clear, whilst higher education attainment seemed protective as there was no association between depression and lower education attainments. ${ }^{12}$ These differences show the importance of understanding population-specific factors associated with depression in order to enhance screening efficiency as a first step to enhancing diagnosis and treatment of primary care patients with depression.

Previous studies in Botswana have estimated a depression prevalence of $28 \%-35 \% .{ }^{24,25}$ However, these studies targeted HIV-infected people and may not be reflective of the primary care population in Botswana. We did not find any studies reporting the prevalence and correlates of depression in the general primary care population in Botswana. This knowledge would help identify the specific sub-population of primary care patients who may benefit from depression screening and appropriate management in Botswana. The aim of this study was to determine the prevalence and correlates of depressive symptoms in two urban primary care settings in Botswana.

\section{Methods}

This article is a sub-analysis of data from a validation study of the Patient Health Questionnaire-9 (PHQ-9) and depression screening questionnaire in Botswana. ${ }^{26}$ The study was conducted in two primary care outpatient health facilities in Gaborone, the capital city of Botswana. One facility, Old Naledi Clinic, is located in a low-income area whilst the other, Village Clinic, is located in a middle- to high-income area. Both are public health facilities offering free healthcare services to citizens. Data were collected for this study on a daily basis during weekdays between May 2019 and June of 2019. Trained research assistants (RAs) enrolled participants from the general outpatient departments at each site; the RAs explained the importance of the study and study procedures to the patients as they waited in the consultation queue. Adult patients aged above 18 years, who could speak Setswana or English (the two official languages), who were not physically acutely ill and did not have a current psychotic illness and who gave signed informed consent were enrolled consecutively. The sampling was carried out using convenience sampling, patients waiting in the queue were approached sequentially to ask if they would be interested in joining the study. Those who consented were then interviewed using a researcher designed demographic questionnaire and the PHQ-9. Patients who were found to be severely depressed or who had suicidal ideation were referred to the psychiatric nurse based at each facility for further assessment and management or referral.

\section{Measures}

A demographic questionnaire was designed to capture the following data: age, gender, income bracket, occupation, education level, marital status, chronic diseases including HIV and psychiatric disease, substance use and family history of chronic disease including psychiatric conditions.

The $P H Q-9$ is a 9-item depression screening tool that has been validated in several primary care settings in Southern Africa that can be self or provider administered. .7,28,29 $^{\text {The }}$ patient is asked if they experience each of the nine symptoms in the questionnaire over the preceding two weeks. Each of the nine questions can be scored from 0 to 3 , indicating increasing frequency from not experiencing the symptom at all to almost daily symptoms. A validation study conducted in Botswana reported the sensitivity and specificity of the PHQ-9 to be $72.4 \%$ and $76.3 \%$, respectively, at a cut-off point of $9.0 \%$ and $68.6 \%$ and $79.6 \%$, respectively, at a cut-off point of $10 .{ }^{26}$

\section{Statistical analysis}

A sample size of 252 was calculated for the main objective of the study, which was to validate the PHQ-9 in this primary care population. ${ }^{26}$ Determining the prevalence of depression was the secondary aim of the study. Assuming the reference proportion of patients with depression is $20 \%$, the study is 
TABLE 1: Demographic characteristics of study participants in two primary care settings in Gaborone, Botswana.

\begin{tabular}{|c|c|c|}
\hline Variable & $N$ & $\%$ \\
\hline \multicolumn{3}{|l|}{ Healthcare facility } \\
\hline ON & 130 & 50.2 \\
\hline VI & 129 & 49.8 \\
\hline \multicolumn{3}{|l|}{ Gender } \\
\hline Female & 173 & 66.8 \\
\hline Male & 85 & 32.8 \\
\hline Missing & 1 & 0.4 \\
\hline \multicolumn{3}{|l|}{ Age } \\
\hline Median (years) & 32 & - \\
\hline IQR & $24-41$ & - \\
\hline \multicolumn{3}{|l|}{ Marital status } \\
\hline Single & 64 & 24.8 \\
\hline In a relationship & 88 & 34.1 \\
\hline Married & 29 & 11.2 \\
\hline Widowed & 8 & 3.1 \\
\hline Divorced & 10 & 3.9 \\
\hline Cohabiting & 59 & 22.9 \\
\hline Missing & 1 & 0.04 \\
\hline \multicolumn{3}{|l|}{ Employment status } \\
\hline Unemployed & 61 & 23.6 \\
\hline Self-employed $\Phi$ & 36 & 13.9 \\
\hline Part-time & 9 & 3.5 \\
\hline Casual labourer & 9 & 3.5 \\
\hline Formal employment & 125 & 48.3 \\
\hline Student & 19 & 7.3 \\
\hline \multicolumn{3}{|l|}{ Religion } \\
\hline Islam & 4 & 1.5 \\
\hline Christianity & 225 & 86.9 \\
\hline African traditional religion & 9 & 3.5 \\
\hline Other & 14 & 5.4 \\
\hline None & 1 & 0.4 \\
\hline Missing & 6 & 2.3 \\
\hline \multicolumn{3}{|l|}{ Education } \\
\hline No school & 6 & 2.3 \\
\hline Primary & 30 & 11.6 \\
\hline Junior Secondary & 85 & 32.8 \\
\hline Senior Secondary & 74 & 28.6 \\
\hline Tertiary & 64 & 24.7 \\
\hline \multicolumn{3}{|l|}{ Diagnosisł: } \\
\hline Diabetes & 5 & 1.9 \\
\hline Stroke/CVA & 6 & 2.3 \\
\hline HIV & 57 & 22.0 \\
\hline Hypertension & 44 & 17.3 \\
\hline Other & 21 & 8.3 \\
\hline None & 142 & 55.6 \\
\hline Missing & 4 & 1.6 \\
\hline \multicolumn{3}{|c|}{ Estimated average monthly income (BWP) } \\
\hline Below 600 & 46 & 17.8 \\
\hline $600-2300$ & 107 & 41.3 \\
\hline 2400-4199 & 44 & 17.0 \\
\hline $4200-6000$ & 23 & 8.9 \\
\hline Above 6000 & 19 & 7.3 \\
\hline Not disclosed & 19 & 7.3 \\
\hline \multicolumn{3}{|l|}{ Substance use } \\
\hline Alcohol only & 81 & 31.3 \\
\hline Dagga/cannabis only & 1 & 0.4 \\
\hline Tobacco only & 4 & 1.5 \\
\hline Others & 33 & 12.7 \\
\hline None & 138 & 53.3 \\
\hline Missing & 2 & 0.8 \\
\hline
\end{tabular}

Table 1 continues on the next column $\rightarrow$
TABLE 1 (Continues...): Demographic characteristics of study participants in two primary care settings in Gaborone, Botswana.

\begin{tabular}{lcc}
\hline Variable & $\boldsymbol{N}$ & $\mathbf{\%}$ \\
\hline Relative with MI & 59 & 23 \\
Yes & 181 & 70.7 \\
No & 61 & 6.3 \\
Do not know & & \\
You with MI & 5 & 1.9 \\
Yes & 251 & 96.9 \\
No & 3 & 1.2 \\
\hline Missing &
\end{tabular}

Note: 1 Botswana pula $=0.091$ United States dollar at time of study.

ON, Old Naledi Clinic; VI, village clinic; IQR, interquartile range; HIV, human immunodeficiency virus infection; MI, mental illness; CVA, cerebrovascular accident; BWP, Botswana pula.

$\dagger$, diagnoses as stated by patient; $\downarrow$, more than one substance or other illicit drug; $\S$, answers may not add up to 259 because more than one response possible for each participant; - informal employment.

adequately powered $(80 \%)$ to detect a minimum $8 \%$ difference in depression prevalence, with a precision level of 0.05 . Initial analysis showed that the data were not normally distributed, we report descriptive data as medians and inter-quartile ranges for continuous data and proportions for categorical data. To test for the association between depression and demographic variables we calculated Pearson's Chi-square. The level of significance was set at 5\%. Spearman's rank correlation was used to determine the association between demographic characteristics and depression using a PHQ-9 cut-off of 10. Multivariate analysis was carried out using Kruskal-Wallis one-way analysis of variance (ANOVA) to determine the association between demographic characteristics and depression.

\section{Ethical considerations}

Full ethical clearance was granted by the University of Botswana Institutional Review Board (UBR/RES/IRB/ BIO/122) and Health Research and Development Division, Botswana Ministry of Health and Wellness (13/18/1). All participants gave written and informed consent to participate in the study. Confidentiality was maintained by use of unidentified data collection forms.

\section{Results \\ Participant characteristics}

The final study sample size was 259, which was slightly larger than the minimum calculated sample size 252 , of these $66.8 \%$ were females, the median age was 32 years. A little over a third of participants identified as not being in a relationship (they were either single, divorced or widowed). Unemployment was high at $23.6 \%$ and about $13 \%$ had less than a primary education. Over half of the study population identified as having no chronic illness whilst $22.4 \%$ identified as being HIV positive. Table 1 shows the demographic characteristics of the participants.

\section{Prevalence of depression}

Seven participants had missing data for some of the PHQ-9 questions. Thus, the PHQ-9 score could not be 
TABLE 2: Association of demographic variables and depression in two primary care settings in Gaborone, Botswana using a Patient Health Questionnaire-9 cut-off score of 10 .

\begin{tabular}{|c|c|c|c|c|c|c|}
\hline \multirow[t]{2}{*}{ Variable } & \multicolumn{2}{|c|}{$\begin{array}{c}\text { No depression (PHQ-9 of }<10), \\
(n=161)\end{array}$} & \multicolumn{2}{|c|}{$\begin{array}{c}\text { Depression (PHQ-9 = } 10 \text { or above), } \\
(n=91)\end{array}$} & \multirow[t]{2}{*}{ Chi-square value } & \multirow[t]{2}{*}{$p$-value } \\
\hline & $N$ & $\%$ & $N$ & $\%$ & & \\
\hline \multicolumn{7}{|l|}{ Gender } \\
\hline Female & 102 & 40.6 & 68 & 27.1 & 3.77 & 0.152 \\
\hline Male & 58 & 23.1 & 23 & 9.2 & - & - \\
\hline \multicolumn{7}{|l|}{ Marital status } \\
\hline Single & 41 & 25.2 & 19 & 11.7 & $9.923 *$ & 0.710 \\
\hline Married & 15 & 9.2 & 14 & 8.6 & - & - \\
\hline Widowed & 7 & 4.3 & 0 & - & - & - \\
\hline Divorced & 6 & 3.7 & 4 & 2.5 & - & - \\
\hline Cohabiting & 41 & 25.2 & 16 & 9.8 & - & - \\
\hline \multicolumn{7}{|l|}{ Employment status } \\
\hline Unemployed & 28 & 11.1 & 32 & 12.7 & 15.139 & 0.002 \\
\hline Informal employment & 31 & 12.3 & 21 & 8.3 & - & - \\
\hline Formal employment & 91 & 36.1 & 30 & 11.9 & - & - \\
\hline Student & 11 & 4.4 & 8 & 3.2 & - & - \\
\hline \multicolumn{7}{|l|}{ Religion } \\
\hline Islam & 3 & 1.2 & 1 & 0.4 & $4.813^{*}$ & 0.269 \\
\hline Christianity & 141 & 57.3 & 77 & 31.3 & - & - \\
\hline ATR & 4 & 1.6 & 5 & 2.0 & - & - \\
\hline Other & 6 & 2.4 & 8 & 3.3 & - & - \\
\hline None & 1 & 0.4 & 0 & - & - & - \\
\hline \multicolumn{7}{|l|}{ Education } \\
\hline No school & 4 & 1.6 & 2 & 0.8 & $2.414 *$ & 0.668 \\
\hline Primary & 17 & 6.7 & 11 & 4.4 & - & - \\
\hline Junior Secondary & 48 & 19.0 & 34 & 13.5 & - & - \\
\hline Senior Secondary & 51 & 20.2 & 22 & 8.7 & - & - \\
\hline Tertiary & 41 & 8.7 & 22 & 8.7 & - & - \\
\hline \multicolumn{7}{|l|}{ Diagnosis } \\
\hline One NCD & 20 & 8.0 & 9 & 3.6 & 2.494 & 0.650 \\
\hline HIV only & 27 & 10.8 & 15 & 6.0 & - & - \\
\hline Comorbidity $\dagger$ & 11 & 4.4 & 11 & 4.4 & - & - \\
\hline None & 90 & 36.1 & 52 & 20.9 & - & - \\
\hline Other & 10 & 4.0 & 4 & 1.6 & - & - \\
\hline \multicolumn{7}{|l|}{ Income } \\
\hline Below P600 & 18 & 7.2 & 28 & 11.2 & $15.323^{*}$ & 0.020 \\
\hline $600-2300$ & 69 & 27.7 & 32 & 12.9 & - & - \\
\hline 2400-4199 & 31 & 12.4 & 12 & 4.8 & - & - \\
\hline $4200-6000$ & 15 & 6.0 & 8 & 3.2 & - & - \\
\hline Above 6000 & 13 & 5.2 & 6 & 2.4 & - & - \\
\hline Not disclosed & 12 & 4.8 & 5 & 2.0 & - & - \\
\hline \multicolumn{7}{|l|}{ Substance use } \\
\hline Alcohol & 52 & 20.8 & 28 & 11.2 & $5.561 *$ & 0.198 \\
\hline Dagga & 1 & 0.4 & 0 & - & - & - \\
\hline Tobacco & 0 & - & 3 & 1.2 & - & - \\
\hline Other & 19 & 7.6 & 12 & 4.8 & - & - \\
\hline None & 89 & 35.6 & 46 & 18.4 & - & - \\
\hline \multicolumn{7}{|l|}{ Relative with MI } \\
\hline Yes & 34 & 13.7 & 24 & 9.6 & $6.793 *$ & 0.097 \\
\hline No & 112 & 44.9 & 63 & 25.3 & - & - \\
\hline Don't know & 14 & 5.6 & 2 & 0.8 & - & - \\
\hline \multicolumn{7}{|l|}{ You with MI } \\
\hline Yes & 1 & 0.4 & 4 & 1.6 & $6.629 *$ & 0.059 \\
\hline No & 158 & 63.5 & 86 & 34.5 & - & - \\
\hline
\end{tabular}

Note: Bold numbers indicate statistically significant $p$-value.

PHQ-9, Patient Health Questionnaire 9; ATR, African traditional religion; NCD, non-communicable disease; MI, mental illness.

*, Fisher's exact test.

$\dagger$, more than one chronic disease in any combination.

calculated for them. Using the remaining sample of 252, the prevalence of depression or depressive symptoms, which was $40.9 \%$, with a $95 \%$ confidence interval (CI)
(34.7, 47.2), using a PHQ-9 cut-off of nine. A slightly lower prevalence of $36.1 \%$, with a $95 \%$ CI $(30.2,42.4)$ was seen when using a higher cut-off of 10 . 


\section{Factors associated with depression}

Table 2 shows the bivariate analysis to determine the level of association between depression (PHQ-9 cut-off 10) and demographic factors of the participants as analysed using Chi-square, $\chi^{2}$ (or Fisher exact test where number of values expected in any cell was less than 5). A positive association was observed between depression and employment (grouped as unemployed, informal employment, formal employment or student) $\left(\chi^{2}=15.139\right.$, and $\left.p=0.002\right)$ and income, $p=0.020$.

\section{Discussion}

The aim of this study was to determine the prevalence and correlates of depression in two urban primary care settings in Botswana. Our findings show that the point prevalence of depressive symptoms was much higher $(40.9 \%)$ ) 95\% CI $(34.7,47.2)$ in this primary care population than current global estimates of depression and previous studies of depressive symptoms in primary care. ${ }^{19,30}$ Our findings are similar to other studies carried out in SSA, reporting a prevalence range of $30 \%-56 \% .^{6,12,17,23}$ It is important to differentiate depressive symptoms as measured in this study from clinical depression, which requires a more robust diagnosis. However, adopting easy to use and freely available screening tools such as the PHQ-9 to screen high-risk patients for depression, may help clinicians in busy health settings identify patients who need further intervention. The findings of this study also support previous assertions that primary care clinicians in African settings should be equipped to diagnose and manage depressive symptoms and depression. . $^{14,31,32}$

Our analysis of the association between depression and participant demographics indicates that the proportion of those with depression was higher in lower income levels and in the unemployed. ${ }^{12,20}$ It has been suggested that the severity of depressive symptoms is inversely related to employment and income. Research shows that the occurrence of depression can also lead to alteration of economic productivity, a decrease of working abilities, social isolation, physical decline and difficulties in solving problems. ${ }^{20}$ Alternatively, being unemployed may negatively affect a person's self-esteem and mood thus triggering depression. ${ }^{33}$ The association of depressive symptoms with unemployment and low income indicates that these factors may be considered as triggers for depression in this primary care population. Considering these patients as high risk for depression may warrant targeted screening and diagnosis. Including occupational rehabilitation and work placement in the depression treatment strategies of this primary care population may help alleviate their depressive symptoms. ${ }^{33,34}$ However, caution should be exercised when analysing this relationship because income and employment status are only part of the broader construct of social status and social support and may not adequately reflect this broader construct.
The effects of income and or unemployment on depression may be mitigated by good social support; a study of 402 patients in outpatient tertiary institutions in Nigeria using the Schedule for Clinical Assessment of Neuropsychiatry (SCAN) found no association between depression and unemployment whilst a study from the United Kingdom found that accounting for debt diminished the effect of income on mental health, that is, being in debt was a stronger determinant of mental illness than income alone. ${ }^{6,35}$ Thus, clinicians must further understand the impact of income and unemployment on a patient's life when assessing for depression.

Although comorbidity with depression and other chronic illnesses have been reported in several studies, we did not find a significant relationship between depression and chronic illnesses. Approximately, a third of the patients in this study identified as having a chronic illness, although this is reflective of primary care settings, these numbers may be too small to detect a difference in the prevalence of depression in patients with versus those without chronic illnesses. Previous studies in Botswana have reported about a quarter to a third of HIV patients in primary care settings had depression, this prevalence was not much different from what we found in this general primary care setting but are much higher than the prevalence we report for HIVinfected patients in this study. ${ }^{24,25}$ Our study was not adequately powered to detect differences in depression by chronic disease; we suggest an adequately powered study to investigate the relationship between depression and chronic illnesses in primary care may help to answer this question better.

We found that a history of previous mental health was not associated with depression in this study population. This finding is unsurprising because common mental illnesses such as anxiety are often undiagnosed. In addition, in this study there were only five people who reported a previous diagnosis of mental illness, this number is most likely insufficient to detect a significant difference.

\section{Limitations}

This study was an observational study conducted in two primary care settings in an urban area, the findings of this study may thus be limited to similar outpatient facilities and not to the general population. The risk for depression in general outpatient facilities may also be different from the risk of depression in primary care settings targeting chronic disease patients. In addition, the study sample was obtained using convenience sample, which further contributed to the selection bias of the study. Patients who agreed to join the study may have been more likely to suspect they had depression than those who refused. This would bias the results such that the effect size was larger than the true state. However, the prevalence of chronic diseases and the proportion of unemployed people in this study are similar to previous reports from Botswana, this indicates that any 
selection bias may be minimal. We recommend future studies using randomised sampling techniques and communitybased studies to determine the prevalence of depression in the general population.

\section{Conclusion}

Our study is the first in Botswana to assess the prevalence of depression or depressive symptoms in patients in routine clinical care, highlighting that there is a need to include depression screening as part of care they receive. We recommend the use of PHQ-9 for depression screening in urban primary care populations in Botswana The association between depression and unemployment and income highlights the importance of social determinants of mental health. We recommend that in addition to the traditional cues for depression screening (low mood and anhedonia), clinicians should have a low threshold for depression screening in unemployed primary care populations similar to ours.

\section{Acknowledgements}

The authors would like to acknowledge the patients and staff of Old Naedi and Village clinics in Gaborone for their time and cooperation. The authors also acknowledge the study research assistants: Golekanye Morutwa, Boitshepo Mosupiemang, Tiro Motsamai, Kebakaone Marumo, Olorato Morerinyane, Kevin Tshidviso and Tebogo Majoo who assisted with data collection and entry.

\section{Competing interests}

The authors declare that they have no financial or personal relationships that may have inappropriately influenced them in writing this article.

\section{Authors' contributions}

K.Mol. was responsible for the research grant for early career researchers, designing the study, initial draft and revisions. K.Mot. was involved in conceptualising, designing, data collection and revisions of draft. G.N.W. was responsible for data analysis, initial draft and revisions. All authors read and approved the final draft.

\section{Funding information}

This study was funded by the University of Botswana Internal funding Round 36.

\section{Data availability}

Data sets are available from Dr. K. Molebatsi at molebatsik@ ub.ac.bw.

\section{Disclaimer}

The views and opinions expressed in this article are those of the authors and do not necessarily reflect the official policy or position of any affiliated agency of the authors.

\section{References}

1. World Health Organization. Depression and other common mental disorders: Global health estimates. Geneva: World Health Organization; 2017.

2. Goldberg $D$. The value of screening in patient populations with high prevalence of a disorder. BMC Med. 2014;12:14. https://doi.org/10.1186/1741-7015-12-14

3. Marcus $M$, Yasamy MT, Van Ommeren M, Chisholm D. Depression, a global public health concern. Geneva: WHO Department of Mental Health and Substance Abuse; 2012.

4. Kessler RC, Bromet EJ. The epidemiology of depression across cultures. Annu Rev Public Health. 2013;34:119-138. https://doi.org/10.1146/annurev-publhealth031912-114409.

5. Tomlinson M, Grimsrud AT, Stein DJ, Williams DR, Myer L. The epidemiology of major depression in South Africa: Results from the South African Stress and Health study. S Afr Med J. 2009;99(5 Pt 2): 367-373.

6. Salihu AS, Udofia O. Prevalence and associated factors of depression among general outpatients in a Tertiary Institution in Kano, North-Western Nigeria. Open J Psychiatry. 2016;6(3):228-236. https://doi.org/10.4236/ojpsych.2016.63028

7. Bernard C, Dabis F, De Rekeneire N. Prevalence and factors associated with depression in people living with HIV in sub-Saharan Africa: A systematic review and meta-analysis. PLoS One. 2017;21(8):e0181960. https://doi.org/10.1371/ journal.pone.0181960

8. Moussavi S, Chatterji S, Verdes E, Tandon A, Patel V, Ustun B. Depression, chronic diseases, and decrements in health: Results from the World Health Surveys. Lancet. 2007;370(9590):851-858. https://doi.org/10.1016/S0140-6736(07)61415-9

9. Voinov B, Richie WD, Bailey RK. Depression and chronic diseases: It is time for a synergistic mental health and primary care approach. Prim Care Companion CNS Disord. 2013;15(2):PCC.12r01468. https://doi.org/10.4088/PCC.12r01468

10. Lofgren SM, Bond DJ, Nakasujja N, Boulware DR. Burden of depression in outpatient HIV-infected adults in sub-Saharan Africa; Systematic review and meta-analysis. AIDS Behav. 2019;24:1752-1764. https://doi.org/10.1007/s10461-019-02706-2

11. Kang H-J, Kim S-Y, Bae K-Y, et al. Comorbidity of depression with physical disorders: Research and clinical implications. Chonnam Med J. 2015;51(1):8. https://doi. org/10.4068/cmj.2015.51.1.8

12. Folb N, Lund C, Fairall LR, et al. Socioeconomic predictors and consequences of depression among primary care attenders with non-communicable diseases in the Western Cape, South Africa: Cohort study within a randomised trial chronic disease epidemiology. BMC Public Health. 2015;15(1):1194. https://doi. org/10.1186/s12889-015-2509-4

13. Clarke DM, Currie KC. Depression, anxiety and their relationship with chronic diseases: A review of the epidemiology, risk and treatment evidence. Med J Aust. 2009;190(S7):S54-S60. https://doi.org/10.5694/j.1326-5377.2009.tb02471.x

14. Siu AL, Bibbins-Domingo K, Grossman DC, et al. Screening for depression in adults: US preventive services task force recommendation statement. JAMA 2016;315(4):380-387. https://doi.org/10.1001/jama.2015.18392

15. Craven MA, Bland R. Depression in primary care: Current and future challenges. Can J Psychiatry. 2013;58(8):442-448. https://doi. org/10.1177/070674371305800802

16. WHO. Depression fact sheet N369 [homepage on the Internet]. Media centre fact sheet. 2020 [cited 2021 April 02]. Available from: https://www.who.int/en/ news-room/fact-sheets/detail/depression

17. Udedi M. The prevalence of depression among patients and its detection by primary health care workers at Matawale Health Centre (Zomba). Malawi Med J. 2014;26(2):34-37.

18. Cameron IM, Lawton K, Reid IC. Recognition and subsequent treatment of patients with sub-threshold symptoms of depression in primary care. J Affect Disord. 2011;130(1-2):99-105. https://doi.org/10.1016/j.jad.2010.10.010

19. Milanović SM, Erjavec K, Poljičanin T, Vrabec B, Brečić P. Prevalence of depression symptoms and associated socio-demographic factors in primary health care patients. Psychiatr Danub. 2015;27(1):31-37.

20. Rizvi SJ, Cyriac A, Grima E, et al. Depression and employment status in primary and tertiary care settings. Can J Psychiatry. 2015;60(1):14-22. https://doi. org/10.1177/070674371506000105

21. Salihu AS. Impact of somatic symptoms on identification of depression among general outpatients by family physicians in North-Western Nigeria. Open Psychiatry. 2015;05(03):278-284. https://doi.org/10.4236/ojpsych.2015.53031

22. Mitchell AJ, Vaze A, Rao S. Clinical diagnosis of depression in primary care: A metaanalysis. Lancet. 2009;374(9690):609-619. https://doi.org/10.1016/S01406736(09)62053-5

23. Adewuya AO, Coker OA, Atilola O, et al. Gender difference in the point prevalence, symptoms, comorbidity, and correlates of depression: Findings from the Lagos
State Mental Health Survey (LSMHS), Nigeria. Arch Womens Ment Health. State Mental Health Survey (LSMHS), Nigeria. Arch Womens
2018;21:591-599. https://doi.org/10.1007/s00737-018-0839-9

24. Lawler K, Mosepele M, Seloilwe E, et al. Depression among HIV-positive individuals in Botswana: A behavioral surveillance. AIDS Behav. 2011;13(1):15. https://doi. org/10.1186/1758-2652-13-15

25. Gupta R, Dandu M, Packel L, et al. Depression and HIV in Botswana: A populationbased study on gender-specific socioeconomic and behavioral correlates. PLoS One. 2010;5(12):e14252. https://doi.org/10.1371/journal.pone.0014252

26. Molebatsi K, Motlhatlhedi K, Wambua GN. The validity and reliability of the Patient Health Questionnaire-9 for screening depression in primary health care patients in Botswana. BMC Psychiatry. 2020;20:295. https://doi.org/10.1186/ s12888-020-02719-5 
27. Bhana A, Rathod SD, Selohilwe O, Kathree T, Petersen I. The validity of the Patient Health Questionnaire for screening depression in chronic care patients in primary health care in South Africa. BMC Psychiatry. 2015;15:118. https://doi. org/10.1186/s12888-015-0503-0

28. Udedi M, Muula AS, Stewart RC, Pence BW. The validity of the Patient Health Questionnaire-9 to screen for depression in patients with type-2 diabetes mellitus in non-communicable diseases clinics in Malawi. BMC Psychiatry. 2019;19(1):81 https://doi.org/10.1186/s12888-019-2062-2

29. Adewuya AO, Ola BA, Afolabi OO. Validity of the Patient Health Questionnaire (PHQ-9) as a screening tool for depression amongst Nigerian university students. J Affect Disord. 2006;96(1-2):89-93. https://doi.org/10.1016/j.jad.2006.05.021

30. Jo SJ, Yim HW, Jeong H, et al. Prevalence of depressive disorder of outpatients visiting two primary care settings. J Prev Med Public Heal. 2015;48(5):257-263. https://doi.org/10.3961/jpmph.15.009
31. Thombs BD, Coyne JC, Cuijpers P, et al. Rethinking recommendations for screening for depression in primary care. Can Med Assoc J. 2012;184(4):413-418. https:// doi.org/10.1503/cmaj.111035

32. Joffres $M$, Jaramillo A, Dickinson J, et al. Recommendations on screening for depression in adults. Can Med Assoc J. 2013;185(12):1067. https://doi. org/10.1503/cmaj.113-2130

33. Carod-Artal FJ. Social determinants of mental health. In: Global mental health Prevention and promotion. 2017. https://doi.org/10.1007/978-3-319-59123-0 4

34. Crost B. Can workfare programs offset the negative effect of unemployment on subjective well-being? Econ Lett. 2016;140:42-47. https://doi.org/10.1016/j econlet.2015.12.007

35. Jenkins $R$, Bhugra $D$, Bebbington $P$, et al. Debt, income and mental disorder in the general population. Psychol Med. 2008;38(10):1485-1493. https://doi. org/10.1017/S0033291707002516 